
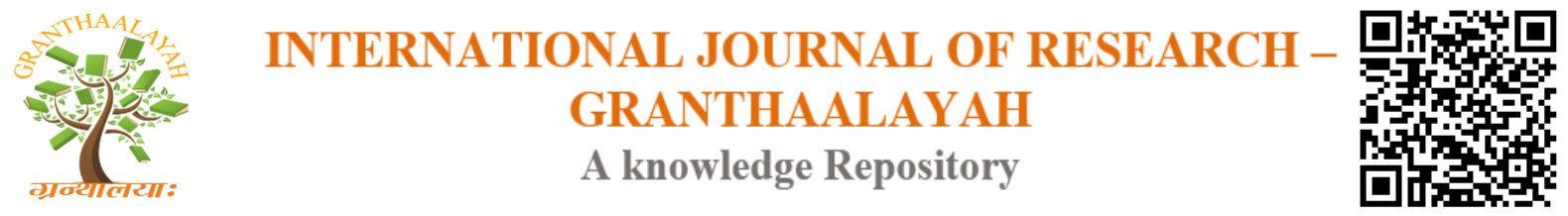

Management

\title{
DATA MINING AND ITS EFFICACY IN KNOWLEDGE MANAGEMENT WITH RESPECT TO HRIS APPLICATION
}

\author{
Ms. Tripti Chopra ${ }^{* 1}$, Dr. Shine David ${ }^{2}$ \\ ${ }^{* 1}$ Research Scholar CPUR, Kota, INDIA \\ ${ }^{2}$ Assistant Professor, IMS Indore, INDIA
}

DOI: https://doi.org/10.29121/granthaalayah.v4.i9.2016.2535

\section{ABSTRACT}

Industries are constantly trying to stay competitive by retaining its reputation in the market in which it is operating. Due to Globalization companies have to rethink their strategies and practices. A company's strategy highly depends upon the use of application and the utilization of resources. Amidst all these $\mathrm{HR}$ factors tend to play a potential role in determining the effectiveness and competitiveness of an organization. HRIS is generally considered as managing people practices using IT enabled services. Thus it is a task of HRIS to cater to the needs of knowledge management .Knowledge management involves the practices which are utilized to get the right people at right time to train them and finally appraising their performance and reward them. This helps in keeping employees satisfied and happy. When the performance of an employee is evaluated a number of techniques are used to mine the utmost knowledge out of them. This is how HRIS is connected to Knowledge management. This empirical study is an effort in knowing the efficacy of data mining techniques in knowledge management and application of HRIS. The major focus of study is to know about the data base of employees for predicting the performance of employees and adopt a knowledge management strategy and the efficacy of data mining in doing so.

Keywords:

Data mining, Knowledge management, HRIS.

Cite This Article: Ms. Tripti Chopra, Dr. Shine David, "DATA MINING AND ITS EFFICACY IN KNOWLEDGE MANAGEMENT WITH RESPECT TO HRIS APPLICATION" International Journal of Research - Granthaalayah, Vol. 4, No. 9 (2016): 55-62.

\section{INTRODUCTION}

In the present era of technological advancement it has become easy to utilize technology for storing, generating and analyzing data. Due to the advancements in technology in business organizations the growth of HR professionals is steady. This has resulted in devotion of more time by HR professionals in strategic decision making because of the automation of transactional HR processes. The data which has been handled manually is now fully automated. This is the 
data which is considered the best for making decision making process swift in an organization. But the major challenge here is to identify which data is useful. This is when we need data mining. Data mining plays a very vital role in knowledge management of an organization when data, information and knowledge can be used interchangeably. Data mining helps in reducing information overload and redundancy. It also facilitates easy and friendly use of the data.

\section{DATA MINING}

Due to its ability to predict methodologies in various fields data mining has gained huge prominence in the society. Data mining may be viewed as the extraction of patterns and models from observed data [1]. Data mining tools aid the discovery of patterns in data. [2], [3], and [4]. Gartner, the global leader in technology research and IT services define mining as the process of discovering meaningful correlations, patterns and trends by sifting through large amount of data stored in depositories [5]. Any data warehouse or data base that is rich and well versed with information shall be mined for efficient decision making. The major specification of data mining is to extract hidden information from a large database. This is due to its new and powerful technology with huge potential to support companies so that they can focus on the most relevant data on their data warehouse. The tools on data mining also help in predicting behaviors and future trends and allow organizations to make knowledge driven and proactive decisions. . The application areas of DM as contained in recent literatures as corroborated in Jiawei (2003) [6] include: medical treatment/disease symptoms identification, retail industry, telephone calling patterns, DNA sequences, natural disaster, web log click stream, financial data analysis, bioinformatics, melody track selection, content-based e-mail processing systems, analyzes of data from specific experiments conducted over time, analysis of nation's census database, and so on.



Learning process

Estimating the accuracy of classifier

Apply to the new data

\section{Classification and Prediction [6]}




\section{KNOWLEDGE MANAGEMENT}

Knowledge being an expensive commodity shall be managed properly to make them valuable asset for the company. Knowledge is a fluid and complex concept. It can be of two types one is explicit and other is tacit. Explicit knowledge is the one which can be easily transferred to others. In contrast tacit knowledge, which is personal knowledge, residing in individual's heads, is very difficult to articulate, codified and communicate [7] (Gupta and McDaniel, 2002). A key objective of $\mathrm{KM}$ is to ensure that the right knowledge is available at the right time in a manner that enables timely decision-making [8] (Hariharan, 2002).

\section{HRIS APPLICATION AND KNOWLEDGE MANAGEMENT}

The advancement in technology has led to many changes in working of HR professionals. HR professionals can now devote more time in making strategic decisions for the firm. Due to this advancement in technology the HR professionals are not required to do work manually. This data is considered to be the best in making decisions swift and easy. But the problem here is, to find the useful data from a huge amount of data. This is when the significance of data mining comes into the picture. Here the data, information and knowledge can be used interchangeably. In Human Resource Information systems Data Mining is considered to be the best tool for knowledge management. When data mining first appeared in 90's it was used for clustering, classifying and predicting the data for efficient decision making. But this is the time when data mining and knowledge discovery are used interchangeably. When we talk about data mining with respect to HRIS it is considered that its exact purpose goes beyond when it touches the stage of knowledge discovery. It plays an important role in compensation and employee retention.

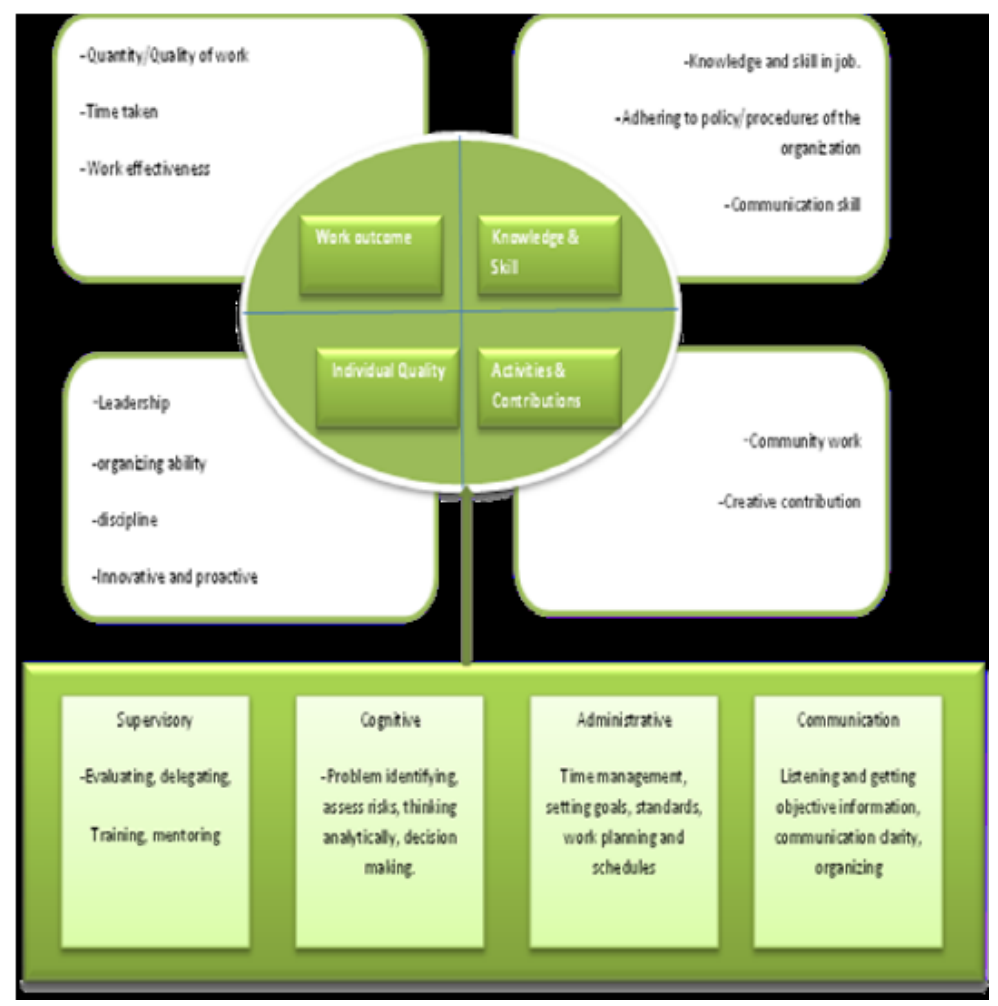

Human Talent predictions using DM techniques [9] 


\section{REVIEW OF LITERATURE}

$\mathrm{KM}$ is about developing, sharing and applying knowledge within organization to gain and sustain a competitive advantage [10] Although DM techniques have attracted all fields like medical, telecommunication, manufacturing, health care and customer relationship, the technique was not of much attraction to the HR fields [11,12]. I t was soon after the establishment of DM in the 90 "s KM also got importance. The rise and growth of KM is one of the managerial responses of the imperial trends associated with the globalization and post industrialism [13].

Data Mining (DM) is a field that has recently attracted the attention of various researchers and organizations. According to Mena (1999) [14]"Data Mining is the process of discovering actionable and meaningful patterns, profiles and trends by sniffing through your data using pattern recognition technologies such as neural networks, machine learning and genetic algorithms" Many organizations have collected and stored vast amount of data. However, they are unable to discover valuable information hidden in the data by transforming these data into valuable and useful knowledge [15]. Knowledge management is a process of data usage [16]. The basis of data mining is a process of using tools to extract useful knowledge from large datasets; data mining is an essential part of knowledge management [17].Wang \& Wang (2008) point that data mining can be useful for KM in two main manners:

i. to share common knowledge of business intelligence (BI) context among data miners and

ii. to use data mining as a tool to extend human knowledge.

Thus, data mining tools could help organizations to discover the hidden knowledge in the enormous amount of data. Data mining is an essential step in the knowledge discovery in databases (KDD) process that produces useful patterns or models from data (Figure 2). The terms of KDD and data mining are different. KDD refers to the overall process of discovering useful knowledge from data. Data mining refers to discover new patterns from a wealth of data in databases by focusing on the algorithms to extract useful knowledge [18].

Liao (2003) [19] classifies KM technologies using seven categories:

1) KM Framework

2) Knowledge-Based Systems (KBS)

3) Data Mining

4) Information and Communication Technology

5) Artificial Intelligence (AI)/Expert Systems (ES)

6) Database Technology (DT)

7) Modeling

A human resource development system should always integrate the organizations' core competencies, knowledge base and the personal dimensions. A competence-based strategy sets the frame and direction for human resource development. (Laakso-Manninen \& Viitala 2007) [20]. A human resource information system is a system used to acquire, store, analyze and distribute information. Surveys indicate that the three most electrified human resource functions are payroll, basic employee records and recruiting (Hahn \& Subramani 2000; Miner \& Crane 1995). [21] 
Since 1991 'Knowledge Management` has taken a formal shape of an established discipline [22] (Nonaka 1991). In today's world, the significance of Knowledge Management (KM) has forced many renowned organizations (i.e., private, public or NGOś) to dedicate their resources to their internal KM efforts, especially as a part of their strategic business processes, information technology, or human resource management departmental operations (Addicott, McGivern \& Ferlie 2006) [23].According to Wright (2005) [24], the term of 'Personal knowledge Management ' was first introduced in 1999 to refer to the process of management of knowledge at the individual level.

\section{PURPOSE OF STUDY}

- To examine the extent to which data mining techniques are supporting knowledge management of Human Resource Information Systems application.

- To evaluate the techniques and overall benefit in knowledge management of Human Resource Information System application.

\section{METHODOLOGY}

The present conclusive study is in the specialized area of HRIS with reference to the influence of MIS in the Medium Scale IT Industries in Bhopal, Indore, Pune and Mumbai.

RESEARCH DESIGN
\begin{tabular}{|l|l|}
\hline Primary Data & Bhopal ,Indore, Pune and Mumbai based medium scale IT industries \\
\hline Secondary Data & Industrial Directory and websites \\
\hline Sample Universe & Employees of IT companies working in HR management \\
\hline Sample Frame & HRIS implementing industries in Bhopal ,Indore, Pune and Mumbai \\
\hline Research Tool & Five Point Likert Scale Questionnaire \\
\hline Sample Size & 96 \\
\hline Sampling Technique & Stratified Random Sampling \\
\hline
\end{tabular}

\section{SAMPLING DESIGN}

The study precisely selected the following employees in the pre-defined approximate ratio of 1:3:5 as respondents from the different medium-scale IT industries of Bhopal Indore, Pune and Mumbai. No. of Respondents from different levels

Top Level Mangers - 10

Middle Level Managers - 34

Processing Managers - 52

\section{DATA COLLECTION}

A pre-tested, well-structured questionnaire is used for the data collection. The questionnaire was distributed to the selected respondents of the medium-scale IT industries and their opinion is 
recorded on 5-point Likert-scale. Further the collected field survey data was processed and prepared the primary data which is the basis for the further data analysis and conclusion.

\section{ANALYSIS AND INTERPRETATION}

This research study aimed at establishing and assessing the data mining techniques in knowledge management of HRIS. It will also establish the support levels using the primary data that pertain the usage intensity of HRIS alongside a demographic factor which is the occupation of the respondents. Cumulative weighted average (CWA) technique was used for the data analysis.

The data regarding the support levels of data mining techniques in Knowledge management of HRIS in the respondents' respective organizations are presented in the table 2.

Table 2: Support Levels in Knowledge Management of HRIS

\begin{tabular}{|l|l|l|l|l|}
\hline Levels & $\begin{array}{l}\text { Characterization/ } \\
\text { clustering }\end{array}$ & Association & Classification & $\begin{array}{l}\text { Cumulative } \\
\text { weighted Average }\end{array}$ \\
\hline Top & 3.35 & 3.83 & 3.22 & 3.47 \\
\hline Middle & 3.49 & 3.91 & 3.52 & 3.64 \\
\hline Lower & 3.18 & 3.42 & 3.29 & 3.30 \\
\hline $\begin{array}{l}\text { Cumulative weighted } \\
\text { average }\end{array}$ & 3.34 & 3.72 & 3.34 & 3.47 \\
\hline
\end{tabular}

\section{INTERPRETATION}

The value of Characterization being offered is 3.34 as per table 2. This comparatively low value of characterization on five point mean rating scale shows that medium scale IT industries of Bhopal, Indore , Pune and Mumbai are low competent in clustering, storing and managing the data using database. While we talk about the association $\mathrm{p}$ [art we can see that its value is quite high which is 3.72. It is a great symbol that these industries are able to associate the data and use it in a better way. It depicts that there are fewer data issues and they can manage their data using HRIS very effectively. When we talk about classification of data for knowledge management we see that its value on five point mean rating scale is 3.47 which is fair enough. The studies suggest that HRIS system act as a value addition and aids in knowledge management.

\section{TECHNIQUES - KNOWLEDGE MANAGEMENT IN HRIS}

The data that was collected through questionnaire in order to assess the techniques information of benefits in knowledge management of HRIS is processed and presented in the table below

Table 3: Credentials of Knowledge Management in HRIS

\begin{tabular}{|l|l|}
\hline Variables & Weighted average \\
\hline Decision support system & 3.63 \\
\hline Performance recording & 3.52 \\
\hline Knowledge creation & 3.67 \\
\hline Business Intelligence & 3.48 \\
\hline Knowledge discovery & 3.72 \\
\hline
\end{tabular}




\begin{tabular}{|l|l|}
\hline Capturing knowledge & 3.56 \\
\hline Average & 3.60 \\
\hline
\end{tabular}

Interpretation table 3 depicts the overall advantages attained with the facilitation of DM techniques in knowledge management of HRIS with the CWA value of 3.60 on 5-point mean rating scale; shows that that medium scale IT industries of Bhopal, Indore, Pune and Mumbai are competent to attain high moderate levels of advantages of knowledge management of HRIS. All the variables except for Business intelligence have average score greater than 3.5.This clearly show that medium scale IT industry are aware about the advantages of data mining in knowledge management with HRIS. The only problem is they are not utilizing it to maximum extent to get maximum return over the investment.

\section{CONCLUSION}

The study evidences efficacy levels of medium-scale textile industries towards knowledge management of HRIS is more than average and suggest that if industries want to make maximum out of it then they have to improvise a bit. If they want to conquer and procure the opportunities then they have to use HRIS effectively. There is a need to focus more on HRIS to increase the efficacy of Data mining in knowledge management. The study shows that the support level of data mining in knowledge management with HRIS is not so strong but reasonably good.

\section{REFERENCES}

[1] Berry, M. J. A., \& Linnof, G, Data mining Techniques, New York: Wiley, (1997).

[2] Agrawal, R., Imielinski, T., and Swami, A., 1993. Mining association rules between sets of items in large databases. In Proceedings of the ACM SIGMOD International Conference on Management of Data (ACM SIGMOD "93), pages 207 - 216, Washington, USA.

[3] Agrawal, R. and Srikant, R., 1994.Fast algorithms for mining association rules. In Proceedings of the 20th International Conference on Very Large Databases (VLDB "94), Santiago, Chile

[4] Agrawal, R. and Shim, K., 1996.Developing tightly coupled data mining applications on a relational database system. In Proceedings of the 2 nd International Conference on Knowledge Discovery in Databases and Data Mining (KDD "96), Portland, Oregon, USA

[5] Data Mining definition Available at http://www.gartner.com/it-glossary/data-mining/ Gupta, A. and McDaniel, J. (2002), 'Creating competitive advantage by effectively managing knowledge management, Journal of knowledge Management Practice, Vol 3, No 2; pp 40-49.

[6] Jiawei, H (2003) Data Mining: Current status and Research Directions ; School of Computing Science, Simon Fraser University, March Burnaby, B.C. Canada ;August http://www.cs.sfu.ca/ han

[7] J. Han and M. Kamber, Data Mining: Concepts and Techniques. San Francisco: Morgan Kaufmann Publisher, 2006.

[8] Hariharan, A. (2002), Knowledge Management: A strategic Tool, Journal of knowledge Management Practice, Vol. 3; No. 3; pp 50-59 
[9] Jantan, H., Hamdan, A. R., \& Othman, Z. A., Human Talent Prediction in HRM using C4.5 Classification Algorithm, (IJCSE) International Journal on Computer Science and Engineering Vol. 02, No. 08, 2010, 2526-2534.

[10] Berson, A., Smith, S.J. \&Thearling, K. (1999).Building Data Mining Applications for CRM. New York: McGraw-Hill.

[11] Ranjan, J. (2008). Data Mining Techniques for better decisions in Human Resource Management Systems .International Journal of Business Information Systems, 3(5), 464481.

[12] Chien, C. F., \& Chen, L. F. (2008). Data mining to improve personnel selection and enhance human capital: A case study in high-technology industry .Expert Systems and Applications, 34(1), 380-290.

[13] Scarbrough, H. and Swan, J. (2001) „Explaining the diffusion of knowledge management: The role of fashion ", British Journal of Management, 12, 3-12 Wiig, K. M. (September 1997) 'Knowledge management: An introduction and Perspective' The Journal of knowledge management, Vol 1, No 1 pp 6-14.

[14] Mena J. (1999), 'Data Mining Your Website', dpDigital Press, ISBN: 1- 55558-222-2, The United States of America.

[15] Petersen, N.J. and Poulfelt, F. (2002) Knowlegde Management in Action: A Study of Knowledge Management in Management Consultancies, Working Paper 1-2002, Kaupmannahöfn: Copenhagen Business School.

[16] J. Han and M. Kamber, Data Mining: Concepts and Techniques. San Francisco: Morgan Kaufmann Publisher, 2006.

[17] Dawei, J. (2011). The Application of Date Mining in Knowledge Management.2011 International Conference on Management of e-Commerce and e-Government, IEEE Computer Society, 7-9. doi: 10.1109/ICMeCG.2011.58

[18] Fayyad, U., Piatetsky-Shapiro, G. \& Smyth, P. (1996). From Data Mining to Knowledge Discovery in Databases.AI Magazine, 17(3), 37-54

[19] Liao, S. (2003). Knowledge management technologies and applications-literature review from 1995 to 2002. Expert Systems with Applications, 25, 155-164. doi:10.1016/S09574174(03)000435

[20] Laakso-Manninen, R. \& Viitala, R. 2007. Competence management and Human Resource Development. A theoretical framework for understanding the practices of modern Finnish organizations. Helsinki. Edita.

[21] Hahn, J. \& Subramani, M. 2000. A Framework of Knowledge Management Systems: Issues and Challenges for Theory and Practice. ICIS 2000 Proceedings Paper28. http://aisel.aisnet.org/icis2000/28

[22] Nonaka, Ikujiro (1991). "The knowledge creating company". Harvard Business Review 69 (6 Nov-Dec): 96-104. http://hbr.harvardbusiness.org/2007/07/the-knowledgecreating-company/es.

[23] Addicott, Rachael; McGivern, Gerry; Ferlie, Ewan (2006). "Networks, Organizational Learning and Knowledge Management: NHS Cancer Networks". Public Money \& Management 26 (2): 87-94. doi:10.1111/j.1467-9302.2006.00506.

[24] Wright, Kirby (2005). "Personal knowledge management: supporting individual knowledge worker performance". Knowledge Management Research and Practice 3 (3): 156-165. doi:10.1057/palgrave.kmrp.8500061 